\title{
Propensities of crack interior initiation and early growth for very-high-cycle fatigue of high strength steels
}

\author{
Youshi Hong*, Zhengqiang Lei, Chengqi Sun, Aiguo Zhao \\ State Key Laboratory of Nonlinear Mechanics (LNM), Institute of Mechanics, Chinese Academy of Sciences, Beijing 100190, China
}

\section{A R T I C L E I N F O}

\section{Article history:}

Received 17 December 2012

Received in revised form 20 February 2013

Accepted 28 February 2013

Available online 14 March 2013

\section{Keywords}

Very-high-cycle fatigue

Fatigue life

FGA

Crack extension rate

High strength steels

\begin{abstract}
A B S T R A C T
Fatigue tests of a high carbon chromium steel were performed using rotating bending and ultrasonic axial cycling. Fatigue crack initiated at specimen interior for very-high-cycle fatigue (VHCF) with fish-eye pattern embracing fine-granular-area (FGA) originated from inclusion. The fatigue life from FGA to fish-eye and from fish-eye to the critical crack size was respectively calculated, so as to estimate the fatigue life contributed by FGA. The crack extension rate within FGA was also estimated. Our results demonstrated that the formation of FGA is responsible for a majority part of total fatigue life.
\end{abstract}

(c) 2013 Elsevier Ltd. All rights reserved.

\section{Introduction}

The topic of very-high-cycle fatigue (VHCF), i.e. the process of fatigue failure beyond $10^{7}$ cycles of loading, has attracted an increasing number of investigations in recent years. The progress of the research on this topic has been summarized in the recent reviews [1-5]. On one hand, this trend is driven by the modern engineering requirement that the design lifetime of many components exceeds $10^{7}$ loading cycles. On the other hand, the behavior of VHCF process, especially the propensities of crack initiation and early growth, differs from what prevail in low-cycle and high-cycle fatigue regimes, and has yet to be clearly understood.

It is known that for VHCF of high strength steels, cracks are prone to initiate at specimen subsurface or interior with a distinct feature of so-called "fish-eye" embracing "fine-granular-area (FGA)" [6-8] (also called "optical-dark-area" [9] or "granularbright-facet" [10]) originated from an inclusion. (Acronym FGA is used in what follows.) The formation of FGA and fish-eye, i.e. the stage of crack initiation and early growth of VHCF, almost dominates the fatigue life [11-15]. During this ultra-long period of cycling, the crack extension rate at its initiation and early growth is estimated as the order of magnitude between $10^{-11}$ and $10^{-12} \mathrm{~m} /$ cycle $[9,12]$.

Based on the premise that the fracture mechanics parameter of stress intensity factor is applicable for fish-eye and FGA, there is an interesting tendency that the values of stress intensity factor range for fish-eye and FGA almost keep constant for high strength steels

\footnotetext{
* Corresponding author. Tel.: +86 10 82543966; fax: +86 1062561284 .

E-mail address: hongys@imech.ac.cn (Y. Hong).
}

$[6,8,13,16-18]$, with the latter comparable to the threshold value of fatigue crack initiation $[6,17,18]$.

The investigations of VHCF behavior were therefore based on the essential characteristics related to fish-eye and FGA so as to explain the dominative mechanism of VHCF damage, and to predict the fatigue strength and fatigue life for the fatigue process containing VHCF regime [11,19-24]. Some models have correlated the fatigue strength to the sizes of FGA and inclusion from which the crack originates $[11,19,20]$, some have taken into account the plastic zone size at the front of initial crack [21,22] and some have been based on the probability or cumulative concept for the simulation [22-24]. Although these models were empirical, they reflected, to some extent, the mechanism of crack initiation and early growth for VHCF.

In this paper, fatigue tests on a high carbon chromium steel were performed with rotating bending and ultrasonic fatigue testing methods for the further investigation on the propensities of crack initiation and early growth for high cycle and VHCF. The fractography of broken specimens was examined via scanning electron microscopy, showing that fatigue crack initiated at specimen interior for VHCF with fish-eye pattern embracing FGA originated from inclusion. The fatigue life from FGA to fish-eye and from fish-eye to the critical crack size was respectively calculated, so as to estimate the fatigue life contributed by FGA. The values of stress intensity factor range at FGA and fish-eye were calculated, and the crack extension rate within FGA was estimated. Combined with our previous results $[8,17,21,22,25]$ and those available in literature $[13,16,20,26]$, we explained that the crack growth process in the early stage of VHCF, namely the formation of FGA, is responsible for a majority part of total fatigue life. The very small value of crack extension rate within FGA was further discussed in the light of 
Tanaka-Mura model [27]. Lastly, the large scattering of fatigue life was also discussed.

\section{Experimental procedure}

The test material of this investigation is a high carbon chromium steel with the main chemical compositions of $1.06 \% \mathrm{C}$ and $1.04 \% \mathrm{Cr}$ (Fe balance). Two types of hour-glass shape specimens were machined from the annealed material bar. The dimensions of the specimens are shown in Fig. 1. The hour-glass shape specimens enable the calculation and the control of the applied stress at the minimum section where the fatigue failure is always located. Such specimens were heat-treated: austenitized at $845^{\circ} \mathrm{C}$ for $2 \mathrm{~h}$ in vacuum, then oil-quenched and tempered for $2.5 \mathrm{~h}$ in vacuum at $150{ }^{\circ} \mathrm{C}$ and $180^{\circ} \mathrm{C}$, respectively. The two groups of specimens are named as TT150 (tempered at $150^{\circ} \mathrm{C}$ ) and TT180 (tempered at $180^{\circ} \mathrm{C}$ ). The surface of the diameter reduced part for each specimen was ground and polished to a smooth finish in order to eliminate the machining scratches. The average ultimate tensile strength is $2163 \mathrm{MPa}$ for TT150 and $1849 \mathrm{MPa}$ for TT180, which were obtained from the tensile tests on four specimens (Ø5 $\mathrm{mm}$ ) per group with the same heat-treatment procedure.

Fatigue tests were performed with two loading schemes, namely rotating bending (RB) and ultrasonic axial cycling (UL).

TT180 specimens were tested via RB method which was accomplished by using a "Giga-Quad" machine at room temperature with the rotating speed of $3150 \mathrm{rpm}$, i.e. the loading frequency being $52.5 \mathrm{~Hz}$. The machine possesses four loading ends and is capable of allowing four specimens to be tested simultaneously. A weight was loaded to the end of each specimen through a fixture as a cantilever type loading with the stress ratio of -1 . The applied maximum stress $\left(\sigma_{\max }\right)$ for TT180 specimens ranged from $730 \mathrm{MPa}$ to $1150 \mathrm{MPa}$, so as to gain the whole spectrum of $S-N$ data for the test material.

TT150 specimens were tested via UL method which was conducted by using a Shimadzu USF-2000 at a resonance frequency of $20 \mathrm{kHz}$ at room temperature, with a resonance interval of $100 \mathrm{~ms}$ per $500 \mathrm{~ms}$ (the testing process interrupted with an interval of $100 \mathrm{~ms}$ for every $500 \mathrm{~ms}$ ) and the stress ratio being -1 . Compressive air was used to cool specimen surface during UL testing. The applied maximum stress for TT150 specimens was within a small range between $860 \mathrm{MPa}$ and $880 \mathrm{MPa}$. This was aimed to examine the scattering characteristics of fatigue strength for the test material.

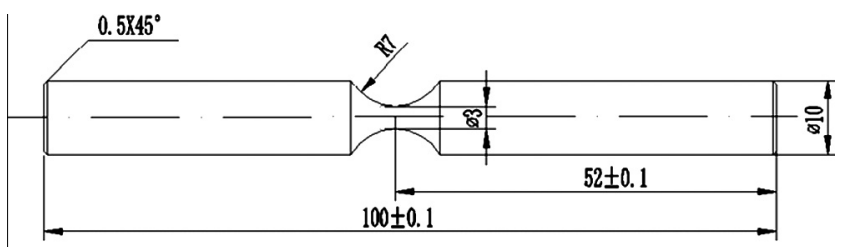

(a)

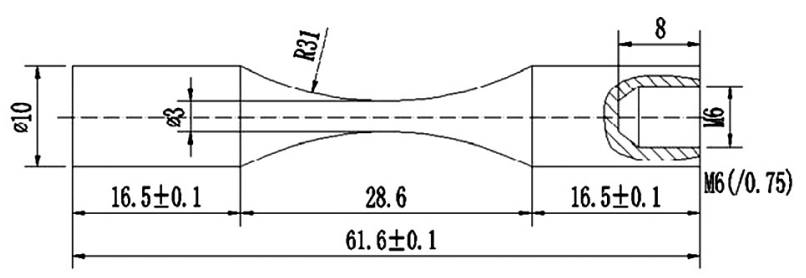

(b)

Fig. 1. Shapes and dimensions (in $\mathrm{mm}$ ) of two types of specimens for fatigue tests, (a) for rotating bending test, the part of $52 \mathrm{~mm}$ for loading, and (b) for ultrasonic axial cycling test.
Fracture surfaces of failure specimens were examined by using a field-emission type of scanning electron microscope (SEM). Local regions of crack initiation were carefully examined. Characteristic dimensions for crack initiation region, i.e. sizes of inclusion, FGA and fish-eye, were measured from SEM photos.

\section{Experimental results}

The SEM photos shown in Fig. 2 are an example of the typical morphology of interior crack initiation for a TT180 specimen experienced VHCF subjected to RB loading, for which the dimensions are: inclusion equivalent diameter $2 a_{\mathrm{Inc}}=35.3 \mu \mathrm{m}$, FGA equivalent diameter $2 a_{\mathrm{FGA}}=66.3 \mu \mathrm{m}$, and fish-eye equivalent diameter $2 a_{\mathrm{fish}}$ eye $=206.2 \mu \mathrm{m}$. To obtain these results, we used $2 a_{\mathrm{Inc}}=\sqrt{\text { are } a_{\mathrm{Inc}}}$, $2 a_{\mathrm{FGA}}=\sqrt{\operatorname{area}_{\mathrm{FGA}}}$, and $2 a_{\text {fisheye }}=\sqrt{\text { area }_{\mathrm{fisheye}}}$, with the values of area being measured from SEM photos. Since RB loading leads to the largest stress at specimen surface, the crack initiation of fish-eye formed underneath the surface, grew towards the surface, and then transitioned into the next stage of crack growth. For UL axial cycling of TT150 specimens, the sites for interior crack initiation were randomly distributed in the cross-section of specimen. The SEM photos of Fig. 3 show the fractography of a TT150 specimen subjected to UL cycling.

Table 1 lists the measured data of the characteristic dimensions for crack initiation of the two groups of specimens together with the values of the applied maximum stress and the fatigue life $\left(N_{f}\right)$. The fatigue life is defined as the number of loading cycles to the complete failure of the specimen. Fig. 4 shows the results of $S-N$ data for the two groups of specimens, in which the symbol styles indicate the crack initiation mode at surface or from interior of specimen. It is shown in Table 1 and Fig. 4 that, for TT180 specimens subjected to RB cycling, the fatigue life ranged from $10^{4}$ to $4 \times 10^{8}$; the $S-N$ data present a duplex or step-wise tendency. It is noted that the stress concentration factor is 1.06 at the minimum section of the specimens used for the rotating bending test, and this value is included in the calculation of applied maximum stress for such specimens. For TT150 specimens subjected to UL cycling at almost the same level of the maximum stress (860-880 MPa), the results show a very large scattering of data distribution. The difference of the fatigue life is as large as three orders of magnitude, ranging from $10^{5}$ to $10^{8}$. The large scattering of fatigue life from this test has been specifically investigated in our recently published paper [28].

Fig. 5 shows the measurements of both FGA and fish-eye sizes as a function of the applied maximum stress. It is shown from Table 1 and Fig. 5 that the FGA sizes are within a relatively small range between 40 and $100 \mu \mathrm{m}$ and the fish-eye sizes are distributed in a large range between 100 and $300 \mu \mathrm{m}$.

The values of stress intensity factor range at the periphery of inclusion $\left(\Delta K_{\mathrm{Inc}}\right)$, FGA $\left(\Delta K_{\mathrm{FGA}}\right)$ and fish-eye $\left(\Delta K_{\text {fisheye }}\right)$ are calculated by using the following equation [10]:

$$
\Delta K=0.5 \sigma_{\max } \sqrt{\pi \sqrt{\text { area }}}
$$

where $\sigma_{\max }$ is the maximum applied stress and $\sqrt{\text { area }}$ is the equivalent size of inclusion, FGA or fish-eye. For the inclusion on the fracture surface of the specimen experienced rotating bending test, the maximum applied stress was calculated via $\sigma_{\max }\left(1-d_{\text {Inc }} / R\right)$, where $R$ is the radius of the cross section, $d_{\text {Inc }}$ is the depth of the inclusion from the surface of specimen, and $\sigma_{\max }$ is the maximum stress at specimen surface. The values for FGA and fisheye were calculated via the same procedure. The calculated values of $\Delta K_{\mathrm{FGA}}$ are shown in Fig. 6, in which most data are between 5 and $6 \mathrm{MPa} \mathrm{m}^{1 / 2}$. The values of $\Delta K_{\text {Inc }}$ are also shown in Fig. 6 , which are below that of $\Delta K_{\mathrm{FGA}}$, displaying a slightly decreasing trend with respect to failure life. 

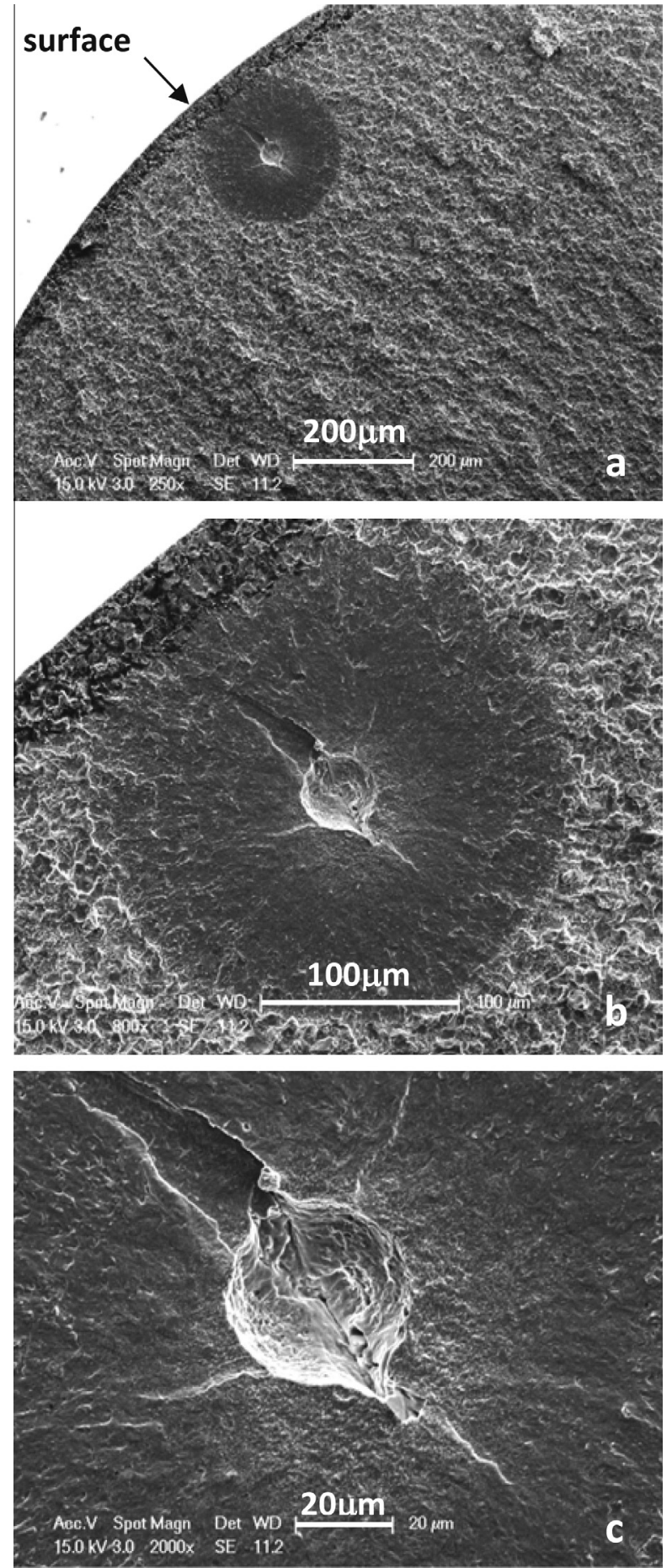

Fig. 2. SEM photos showing fractography of a TT180 specimen $\left(\mathrm{RB}-4, \sigma_{\max }=808-\right.$ MPa, $N_{f}=1.79 \times 10^{7}$ ); (a) crack initiation underneath specimen surface with whole fish-eye morphology, (b) enlargement of fish-eye region and (c) enlargement of central region of fish-eye showing FGA surrounding the crack origin.

The values of $\Delta K_{\text {fisheye }}$ are shown in Fig. 7, which maintain constant around $10 \mathrm{MPa} \mathrm{m}{ }^{1 / 2}$.

\section{Discussion}

\subsection{Stress intensity factor range for FGA}

The present results show that the sizes of FGA distribute within a given range and the values of $\Delta K_{\mathrm{FGA}}$ are converged to the magni-
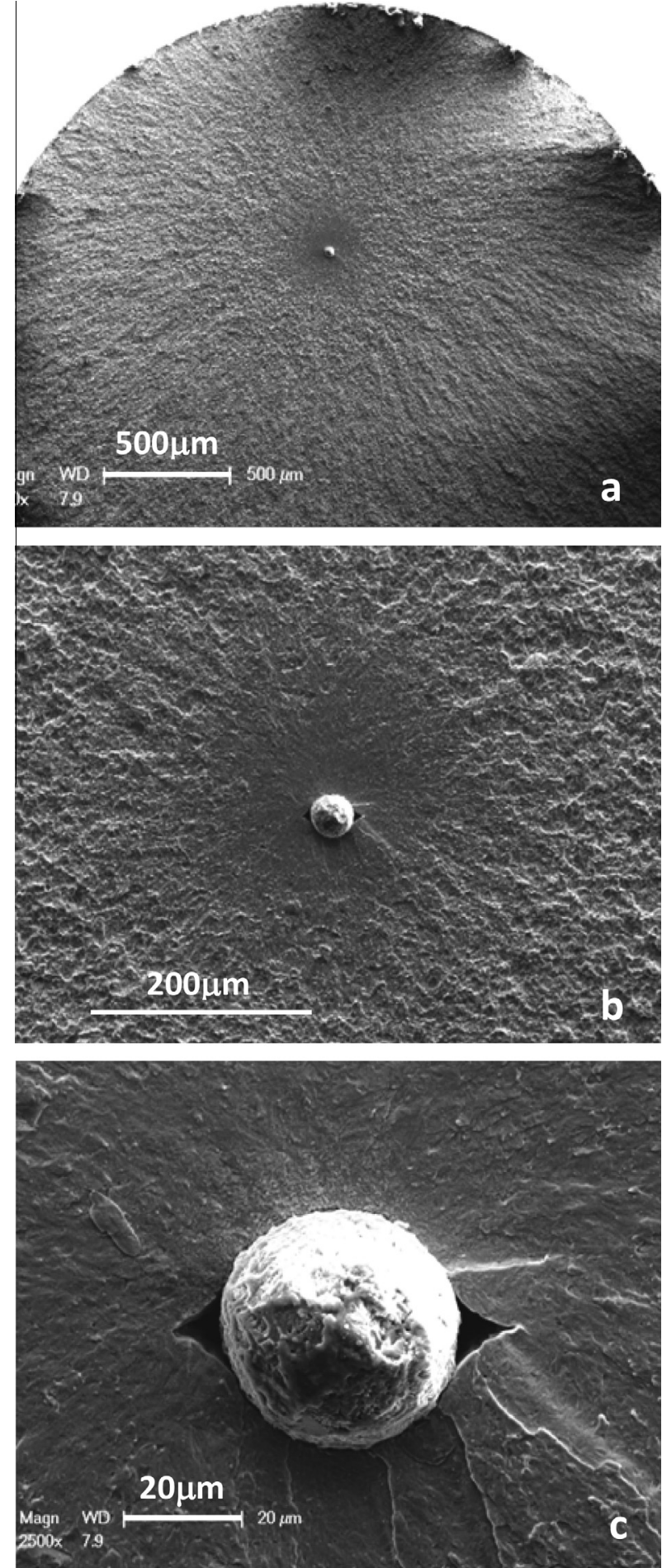

Fig. 3. SEM photos showing fractography of a TT150 specimen (UL-6, $\sigma_{\max }=860$ MPa, $N_{f}=2.81 \times 10^{6}$ ); (a) crack initiation in specimen interior with whole fish-eye morphology, (b) enlargement of fish-eye region and (c) enlargement of central region of fish-eye showing crack origin.

tude between 5 and 6 MPa $\mathrm{m}^{1 / 2}$ (Fig. 6). This is consistent with our previous result that the values of $\Delta K_{\mathrm{FGA}}$ maintain constant with the average value close to the crack growth threshold $\left(\Delta K_{\mathrm{th}}\right)$ [21].

Here, we added additional data from our previous results obtained from a similar steel [21] and others obtained also from similar steels in literature $[13,16,20,26]$ to demonstrate the relationship between $\Delta K$ and $\sigma_{\max }$, and the results are shown in 
Table 1

Measurement results of crack initiation parameters with the data of applied maximum stress and fatigue life for TT150 (UL-1-UL-13) and TT180 (RB-1-RB-8) specimens.

\begin{tabular}{|c|c|c|c|c|c|}
\hline Specimen code & $\sigma_{\max }(\mathrm{MPa})$ & $N_{f}$ & $2 a_{\mathrm{Inc}}(\mu \mathrm{m})$ & $2 a_{\mathrm{FGA}}(\mu \mathrm{m})$ & $2 a_{\text {fisheye }}(\mu \mathrm{m})$ \\
\hline RB-1 & 850 & $5.60 \times 10^{6}$ & 38.1 & 45.5 & 160.5 \\
\hline RB-2 & 850 & $9.64 \times 10^{6}$ & 28.2 & 44.4 & 121.9 \\
\hline RB-3 & 808 & $2.09 \times 10^{7}$ & 30.1 & 37.8 & 108.3 \\
\hline RB-4 & 808 & $1.79 \times 10^{7}$ & 35.3 & 66.3 & 206.2 \\
\hline RB-5 & 775 & $2.40 \times 10^{7}$ & 46.8 & 78.8 & 160.2 \\
\hline RB-6 & 775 & $3.08 \times 10^{7}$ & 39.5 & 66.3 & 164.2 \\
\hline RB-7 & 750 & $5.08 \times 10^{7}$ & 39.9 & 76.9 & 163.6 \\
\hline $\mathrm{RB}-8$ & 738 & $3.89 \times 10^{8}$ & 42.3 & 106.0 & 300.3 \\
\hline UL-1 & 860 & $4.53 \times 10^{5}$ & 41.1 & 43.3 & 208.1 \\
\hline UL-2 & 860 & $7.15 \times 10^{5}$ & 40.1 & 45.4 & 189.6 \\
\hline UL-3 & 860 & $6.06 \times 10^{5}$ & 59.5 & 63.2 & 200.8 \\
\hline UL-4 & 880 & $7.05 \times 10^{5}$ & 52.1 & 54.1 & 183.9 \\
\hline UL-5 & 880 & $1.67 \times 10^{6}$ & 48.9 & 55.8 & 138.1 \\
\hline UL-6 & 860 & $2.81 \times 10^{6}$ & 37.5 & 44.5 & 220.4 \\
\hline UL-7 & 860 & $7.20 \times 10^{6}$ & 36.7 & 43.7 & 247.1 \\
\hline UL-8 & 860 & $7.33 \times 10^{6}$ & 32.5 & 54.4 & 197.6 \\
\hline UL-9 & 880 & $1.09 \times 10^{7}$ & 29.5 & 37.6 & 197.4 \\
\hline UL-10 & 880 & $1.02 \times 10^{7}$ & 29.2 & 50.4 & 155.9 \\
\hline UL-11 & 880 & $5.54 \times 10^{7}$ & 19.9 & 39.6 & 95.5 \\
\hline UL-12 & 860 & $1.43 \times 10^{8}$ & 19.5 & 37.5 & 247.0 \\
\hline UL-13 & 880 & $1.29 \times 10^{8}$ & 30.8 & 52.8 & 151.3 \\
\hline
\end{tabular}

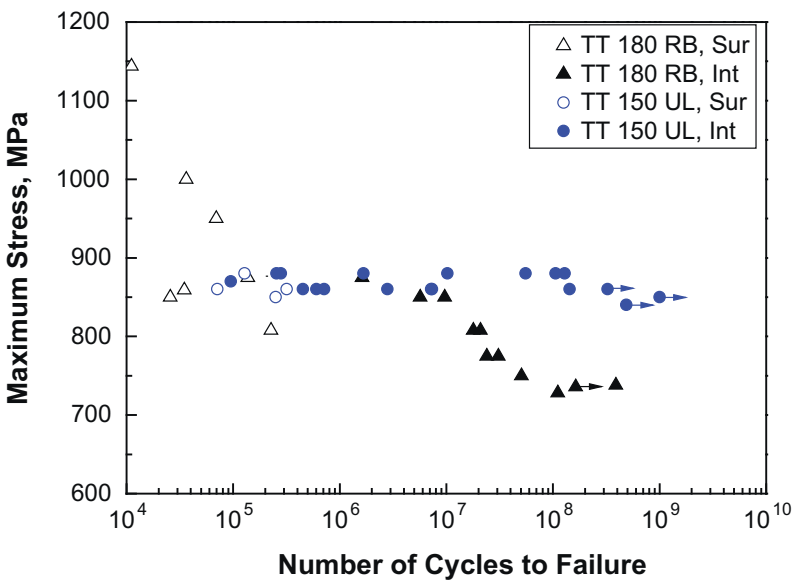

Fig. 4. Fatigue test results of $S-N$ data for TT150 and TT180 specimens. (Sur: crack surface initiation, Int: crack interior initiation, symbol with arrow: no broken.)

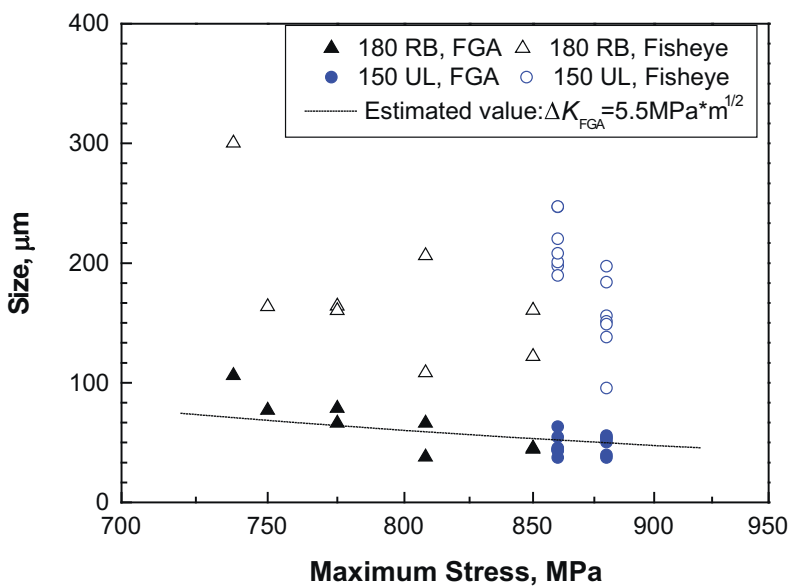

Fig. 5. FGA and fish-eye sizes versus applied maximum stress for TT150 and TT180 specimens.

Fig. 8. Note that the relation between $\Delta K$ and $\sigma_{\max }$ is given by Eq. (1) and the two curves in Fig. 8 are as the lower bound $\left(\Delta K_{\mathrm{FGA}}=4-\right.$ $\left.\mathrm{MPa} \mathrm{m}^{1 / 2}\right)$ and the upper bound $\left(\Delta K_{\mathrm{FGA}}=6 \mathrm{MPa} \mathrm{m}^{1 / 2}\right)$. This range

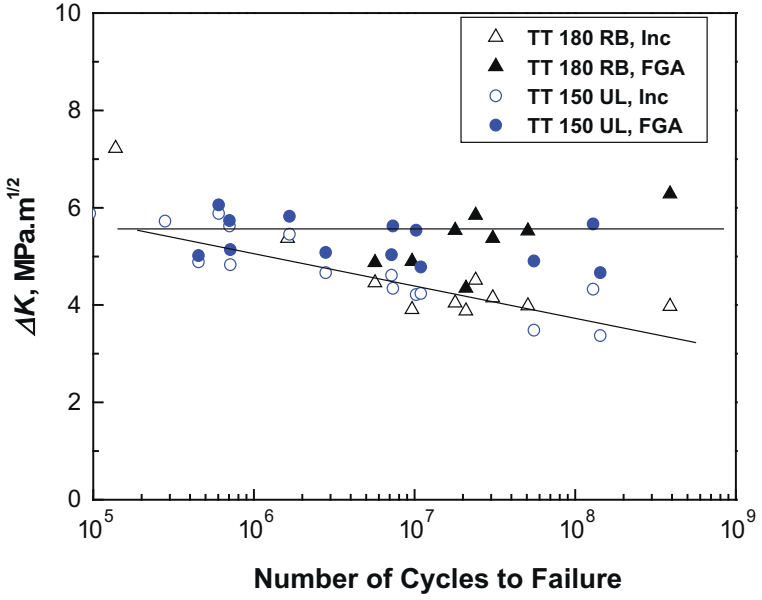

Fig. 6. Stress intensity factor range of FGA $\left(\Delta K_{\mathrm{FGA}}\right)$ and inclusion $\left(\Delta K_{\mathrm{Inc}}\right)$ as a function of fatigue life for TT150 and TT180 specimens.

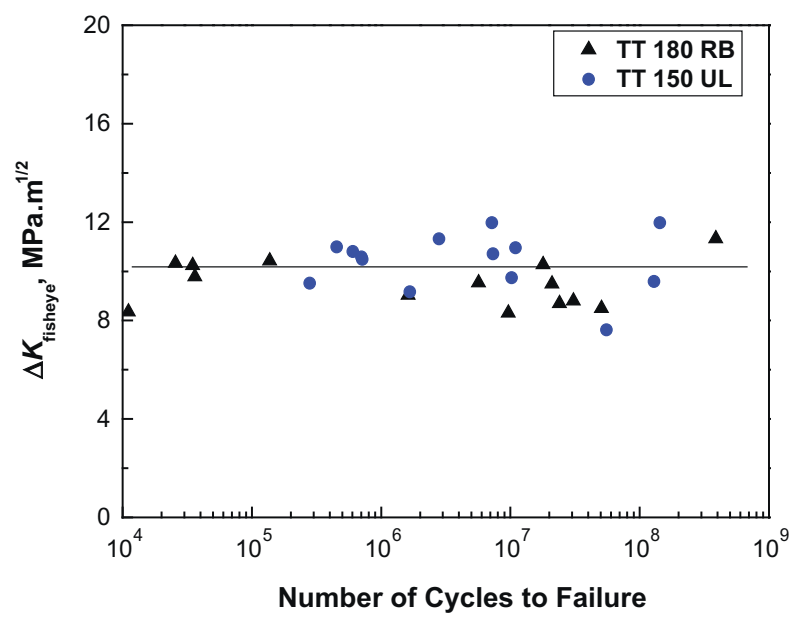

Fig. 7. Stress intensity factor range of fish-eye $\left(\Delta K_{\text {fisheye }}\right)$ as a function of fatigue life for TT150 and TT180 specimens. 


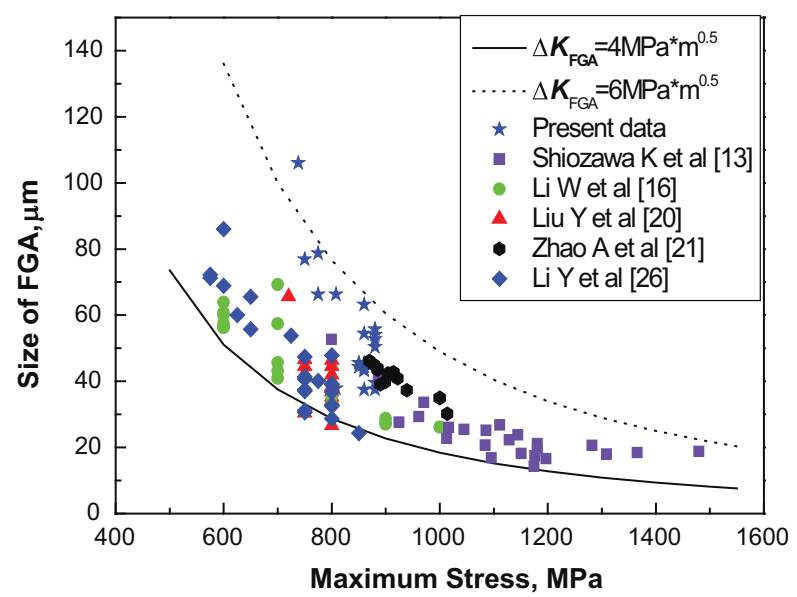

Fig. 8. FGA size as a function of $\sigma_{\max }$ for present data and many others from literature; the solid curve representing the lower bound $\left(\Delta K_{\mathrm{FGA}}=4 \mathrm{MPa} \mathrm{m}^{1 / 2}\right)$ and the dotted curve representing the upper bound $\left(\Delta K_{\mathrm{FGA}}=6 \mathrm{MPa} \mathrm{m}^{1 / 2}\right)$.

corresponds to the threshold value of crack initiation $\left(\Delta K_{\mathrm{th}}\right)$ for this type of steels, for which the value of $\Delta K_{\text {th }}$ is around $5 \mathrm{MPa} \mathrm{m}^{1 / 2}$ as reported in Ref. [10]. It is worth noting that the lower bound value $\left(\Delta K_{\mathrm{FGA}}=4 \mathrm{MPa} \mathrm{m}{ }^{1 / 2}\right)$ and the upper bound value $\left(\Delta K_{\mathrm{FGA}}=6\right.$ MPa $\mathrm{m}^{1 / 2}$ ) in Fig. 8 are based on the consideration that these two bounding curves envelop more than $95 \%$ of the datum points and with the $\Delta K_{\text {th }}\left(5 \mathrm{MPa} \mathrm{m}^{1 / 2}\right)$ as the median value. The present investigation confirms that the equivalent diameter of FGA is the intrinsic characteristic size of crack initiation for the fatigue crack originating from the interior of specimen. It is proposed that for crack interior initiation mode, there exists an intrinsic characteristic size related to $\Delta K_{\mathrm{th}}$. In some cases, the pattern of this size is clearly observed like FGA. However in other cases, although the pattern of this size is not clear, the size intrinsically exists. Based on this, one is able to estimate the fatigue life contributed by crack initiation and early growth, and to estimate the crack extension rate in the crack initiation stage within FGA.

\subsection{Estimation of fatigue life for FGA}

Fig. 9 is a schematic drawing to illustrate the general picture of fatigue crack origination from the interior of specimen as shown in Figs. 2 and 3 . As revealed by the present results together with previous ones, the value of $\Delta K_{\mathrm{FGA}}$ corresponds to that of $\Delta K_{\mathrm{th}}$. It is assumed that Paris relation is acceptable to describe the crack growth process after $\Delta K_{\mathrm{th}}$. Therefore, Paris equation is used to calculate the fatigue life from the boundary of FGA to that of fish-eye $\left(N_{1}\right)$ and the fatigue life from fish-eye to the critical boundary given by the fracture toughness of the material $\left(N_{2}\right)$. The equations for $N_{1}$ are:

$\frac{\mathrm{d} a}{\mathrm{~d} N}=A \Delta K^{m}$

$N_{1}=\frac{2}{(m-2) A Y^{m} \Delta \sigma^{m}}\left[\frac{1}{a_{\mathrm{FGA}}^{(m-2) / 2}}-\frac{1}{a_{\text {fisheye }}^{(m-2) / 2}}\right]$

where $A$ and $m$ are the parameters in relation with the given material, and $Y$ is the related shape factor and is taken as $0.5 \sqrt{\pi}$. For the material tested in this investigation, we noticed a similar case for the crack growth data [10] and obtained the values of $A=1.03 \times 10^{-12}$ and $m=3.28$ with respect to the dimensions of $\mathrm{d} a / \mathrm{d} N(\mathrm{~m} /$ cycle $)$ and $\Delta K\left(\mathrm{MPa} \mathrm{m}^{1 / 2}\right)$, which were fitted by the least square method with the fatigue crack growth data in Paris region

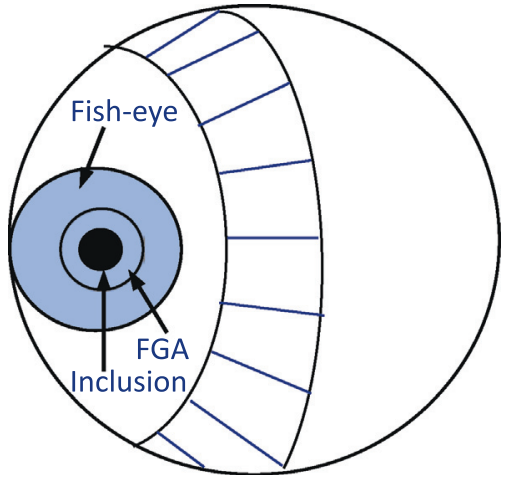

Fig. 9. Schematic of fracture surface especially showing crack interior initiation with the morphology of inclusion, FGA and fish-eye.

for a similar type of steel in Ref. [10]. Thus, the values of $A$ and $m$ were used in the fatigue life estimation.

The results of $N_{1}$ and $N_{2}$ for each specimen of the two groups are listed in Table 2 . Therefore, the fatigue life contributed by crack initiation $\left(N_{i}\right)$ is $N_{i}=N_{f}-N_{1}-N_{2}$. The values of $N_{i} / N_{f}$ for each specimen of the two groups are obtained (listed in Table 2 and plotted in Fig. 10). A group of our previous data [21] are also added to Fig. 10. For the sake of clarity, the data of $N_{f}$ are again listed in Table 2.

It is observed from Fig. 10 and Table 2 that the value of $N_{i} / N_{f}$ increases dramatically with total fatigue life $\left(N_{f}\right)$. The crack initiation life $\left(N_{i}\right)$ contributed by the formation of FGA is less than $70 \%$ when the total fatigue life is below $10^{6}$ cycles. For total fatigue life between $10^{6}$ and $10^{7}$ cycles, the ratio of $N_{i} / N_{f}$ increases to the range between $70 \%$ and $95 \%$, and for the total fatigue life beyond $10^{7} \mathrm{cy}$ cles, i.e. the fatigue including VHCF regime, the value of $N_{i} / N_{f}$ is larger than $95 \%$. Especially for the total fatigue life above $5 \times 10^{7}$ cycles, the value of $N_{i} / N_{f}$ is larger than $99 \%$. It is evident that for fatigue damage including VHCF regime, the fatigue life is almost consumed by the crack initiation process of FGA formation.

\subsection{Estimation of crack extension rate within FGA}

The values of average crack extension rate within FGA were readily calculated from the FGA size and the fatigue life consumed by this region, and the results are shown in Fig. 11 and Table 2. It is observed that the values of crack extension rate within FGA, da/ $\left.\mathrm{d} N\right|_{\mathrm{FGA}}$, are between $10^{-11}$ and $10^{-13} \mathrm{~m} /$ cycle, and the value decreases with fatigue life, $N_{f}$. For $N_{f}$ between $10^{6}$ and $10^{7}$ (high cycle fatigue regime), the values of $\mathrm{d} a /\left.\mathrm{d} N\right|_{\mathrm{FGA}}$ are within the range of $10^{-11}-10^{-12} \mathrm{~m} /$ cycle. For $N_{f}$ between $10^{7}$ and $4 \times 10^{8}$ (VHCF regime), the values of $\mathrm{d} a /\left.\mathrm{dN}\right|_{\mathrm{FGA}}$ are in the range from $10^{-12}$ to $10^{-13} \mathrm{~m} /$ cycle.

Here, the model of blocking dislocations at an inclusion is used to discuss the small value of fatigue crack extension rate within FGA. For this, the model proposed by Tanaka and Mura [27] is introduced, which takes into account the resistance effect of irreversible dislocations, so as to demonstrate the reduction of fatigue strength due to the existence of inclusion and to evaluate the fatigue crack initiation life:

$N_{i}=\frac{2 G W_{s}}{\left(\Delta \tau-2 \tau_{f}\right)^{2} a_{\operatorname{Inc}}}$

where $N_{i}$ is the number of cycles related to crack initiation, $G$ is the bulk shear modulus of matrix, $W_{s}$ is the specific fracture energy, $\Delta \tau$ is the range of local shear stress, $\tau_{f}$ is the friction stress that needs to be overcome for the dislocation movement, and $a_{\mathrm{Inc}}$ is the radius of inclusion. This model was once used for VHCF crack initiation with FGA [29]. Based on the von Mises yield criterion, $\Delta \tau$ and $\tau_{f}$ are ex- 
Table 2

Results of da/d $N$ within FGA, $N_{1}, N_{2}$, and $N_{i}$ for TT150 (UL-1-UL-13) and TT180 (RB-1-RB-8) specimens.

\begin{tabular}{|c|c|c|c|c|c|}
\hline Specimen code & $N_{f}$ & $\begin{array}{l}N_{2}\left(N_{2} / N_{f}\right) \\
a_{\text {fisheye }} \text { to } a_{K 1 \mathrm{c}}\end{array}$ & $\begin{array}{l}N_{1}\left(N_{1} / N_{f}\right) \\
a_{\text {FGA }} \text { to } a_{\text {fisheye }}\end{array}$ & $\begin{array}{l}N_{i} / N_{f} \\
a<a_{\mathrm{FGA}}\end{array}$ & $\begin{array}{l}\mathrm{d} a / \mathrm{d} N(\mathrm{~m} / \text { cycle }) \\
a<a_{\mathrm{FGA}}\end{array}$ \\
\hline RB-1 & $5.60 \times 10^{6}$ & $5.78 \times 10^{4}(1.02 \%)$ & $3.71 \times 10^{5}(6.54 \%)$ & $92.5 \%$ & $1.41 \times 10^{-12}$ \\
\hline RB-2 & $9.64 \times 10^{6}$ & $7.18 \times 10^{4}(0.75 \%)$ & $3.39 \times 10^{5}(3.51 \%)$ & $95.7 \%$ & $1.75 \times 10^{-12}$ \\
\hline RB-3 & $2.09 \times 10^{7}$ & $9.28 \times 10^{4}(0.44 \%)$ & $4.28 \times 10^{5}(2.04 \%)$ & $97.5 \%$ & $3.75 \times 10^{-13}$ \\
\hline RB-4 & $1.79 \times 10^{7}$ & $5.55 \times 10^{4}(0.31 \%)$ & $3.51 \times 10^{5}(1.96 \%)$ & $97.7 \%$ & $1.77 \times 10^{-12}$ \\
\hline RB-5 & $2.40 \times 10^{7}$ & $7.83 \times 10^{4}(0.33 \%)$ & $3.22 \times 10^{5}(1.34 \%)$ & $98.3 \%$ & $1.35 \times 10^{-12}$ \\
\hline RB-6 & $3.08 \times 10^{7}$ & $7.68 \times 10^{4}(0.25 \%)$ & $3.72 \times 10^{5}(1.21 \%)$ & $98.5 \%$ & $8.83 \times 10^{-13}$ \\
\hline RB-7 & $5.08 \times 10^{7}$ & $8.57 \times 10^{4}(0.17 \%)$ & $3.87 \times 10^{5}(0.76 \%)$ & $99.1 \%$ & $7.35 \times 10^{-13}$ \\
\hline $\mathrm{RB}-8$ & $3.89 \times 10^{8}$ & $5.37 \times 10^{4}(0.01 \%)$ & $3.69 \times 10^{5}(0.09 \%)$ & $99.9 \%$ & $1.64 \times 10^{-13}$ \\
\hline UL-1 & $4.53 \times 10^{5}$ & $4.49 \times 10^{4}(9.91 \%)$ & $3.26 \times 10^{5}(72.04 \%)$ & $18.1 \%$ & $2.67 \times 10^{-11}$ \\
\hline UL-2 & $7.15 \times 10^{5}$ & $4.85 \times 10^{4}(6.79 \%)$ & $3.10 \times 10^{5}(43.45 \%)$ & $49.8 \%$ & $1.48 \times 10^{-11}$ \\
\hline UL-3 & $6.06 \times 10^{5}$ & $4.62 \times 10^{4}(7.64 \%)$ & $2.41 \times 10^{5}(39.75 \%)$ & $52.6 \%$ & $1.16 \times 10^{-11}$ \\
\hline UL-4 & $7.05 \times 10^{5}$ & $4.61 \times 10^{4}(6.54 \%)$ & $2.50 \times 10^{5}(35.44 \%)$ & $58.0 \%$ & $4.89 \times 10^{-12}$ \\
\hline UL-5 & $1.67 \times 10^{6}$ & $5.81 \times 10^{4}(3.49 \%)$ & $2.32 \times 10^{5}(13.91 \%)$ & $82.6 \%$ & $4.95 \times 10^{-12}$ \\
\hline UL-6 & $2.81 \times 10^{6}$ & $4.27 \times 10^{4}(1.52 \%)$ & $3.21 \times 10^{5}(11.46 \%)$ & $87.0 \%$ & $2.87 \times 10^{-12}$ \\
\hline UL-7 & $7.20 \times 10^{6}$ & $3.87 \times 10^{4}(5.38 \%)$ & $3.30 \times 10^{5}(4.58 \%)$ & $94.9 \%$ & $1.02 \times 10^{-12}$ \\
\hline UL-8 & $7.33 \times 10^{6}$ & $4.69 \times 10^{4}(0.64 \%)$ & $2.71 \times 10^{5}(3.70 \%)$ & $95.7 \%$ & $3.13 \times 10^{-12}$ \\
\hline UL-9 & $1.09 \times 10^{7}$ & $4.35 \times 10^{4}(0.39 \%)$ & $3.35 \times 10^{5}(3.06 \%)$ & $96.5 \%$ & $7.59 \times 10^{-13}$ \\
\hline UL-10 & $1.02 \times 10^{7}$ & $5.28 \times 10^{4}(0.52 \%)$ & $2.58 \times 10^{5}(2.52 \%)$ & $97.0 \%$ & $2.13 \times 10^{-12}$ \\
\hline UL-11 & $5.54 \times 10^{7}$ & $7.72 \times 10^{4}(0.14 \%)$ & $2.88 \times 10^{5}(0.52 \%)$ & $99.3 \%$ & $3.57 \times 10^{-13}$ \\
\hline UL-12 & $1.43 \times 10^{8}$ & $3.87 \times 10^{4}(0.03 \%)$ & $3.70 \times 10^{5}(0.26 \%)$ & $99.7 \%$ & $1.26 \times 10^{-13}$ \\
\hline UL-13 & $1.29 \times 10^{8}$ & $5.41 \times 10^{4}(0.04 \%)$ & $2.47 \times 10^{5}(0.19 \%)$ & $99.8 \%$ & $1.71 \times 10^{-13}$ \\
\hline
\end{tabular}

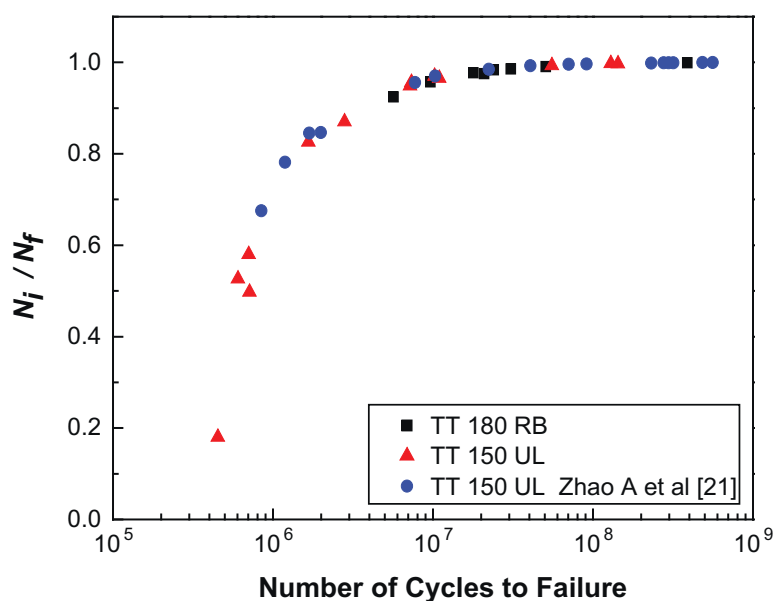

Fig. 10. Normalized crack initiation life, i.e. the fraction of fatigue life due to crack initiation at FGA, as a function of total fatigue life.

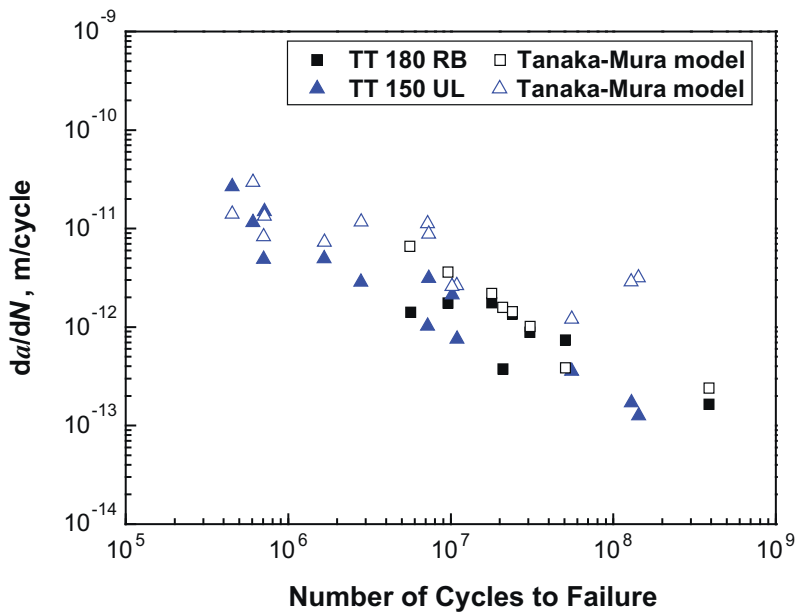

Fig. 11. Crack extension rate within FGA as a function of fatigue life for TT150 and TT180 specimens; solid points from experimental estimation and hollow points from Tanaka-Mura model calculation. pressed as the function of loading stress $\Delta \sigma$ and fatigue limit $\Delta \sigma_{R}$ [29]:

$\Delta \tau=\frac{\sqrt{2}}{3} \Delta \sigma$

$\tau_{f}=\frac{1}{2}\left(\frac{\sqrt{2}}{3} \Delta \sigma_{R}\right)$

For a large number of data for VHCF crack initiation with FGA of high strength steels, the fatigue strength at $10^{7}$ cycles of loading is $0.468 \sigma_{b}[2]$ ( $\sigma_{b}$ is tensile strength), and the fraction of activated irreversible dislocations is small during each loading cycle [30]. Thus, it is assumed that the fraction of irreversible dislocations $p$ is dependent on the stress level, namely:

$p=A^{\prime}\left(\frac{\Delta \sigma-\Delta \sigma_{R}}{\Delta \sigma}\right)^{\alpha}$

where $A^{\prime}$ and $\alpha$ are the parameters fitted by experimental data. Thus the formula for the fatigue life with inclusion initiation is written as:

$N_{i}=A\left(\frac{\Delta \sigma-\Delta \sigma_{R}}{\Delta \sigma}\right)^{\alpha} \frac{1}{\left(\Delta \sigma-\Delta \sigma_{R}\right)^{2} a_{\mathrm{Inc}}}$

Eq. (8), based on the Tanaka-Mura model, conveys the variation of fatigue crack initiation life as a function of related inclusion size. Fig. 12 is a schematic showing that a larger value of inclusion size $a_{\text {Inc,2 }}$ evidently induces a shorter value of fatigue life and a faster crack extension rate. From Eq. (8), the fatigue crack extension rate $\mathrm{d} a_{\text {Inc }} / \mathrm{d} N$ for a crack with the equal length of $a_{\text {Inc }}$ can be estimated by

$\frac{\mathrm{d} a_{\text {Inc }}}{\mathrm{d} N}=\lim _{\Delta N \rightarrow 0} \frac{\left(a_{\text {Inc }}+\Delta a\right)-a_{\text {Inc }}}{(N+\Delta N)-N}$

In fact, Eq. (9) is further derived by taking the deviation of inclusion size, such that:

$\frac{\mathrm{d} a}{\mathrm{~d} N}=-\frac{1}{A}\left(\frac{\Delta \sigma-\Delta \sigma_{R}}{\Delta \sigma}\right)^{-\alpha}\left(\Delta \sigma-\Delta \sigma_{R}\right)^{2} a^{2}$

Eq. (10) expresses the resultant fatigue crack extension rate due to fatigue failure originated from inclusion. Note that the minus sign in the right hand side of Eq. (10) means a larger inclusion will 


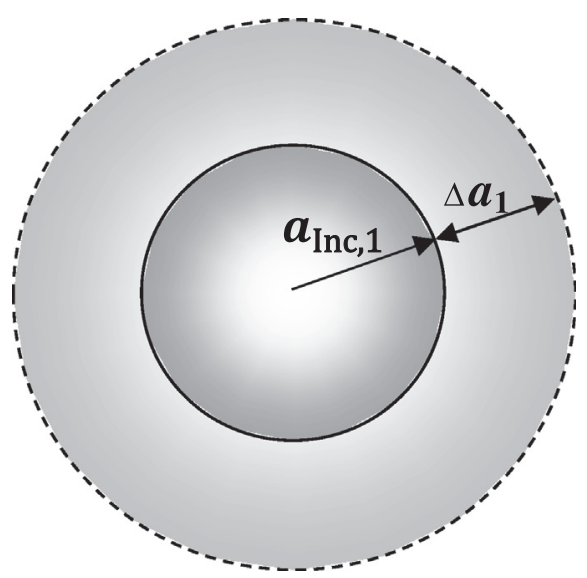

(a)

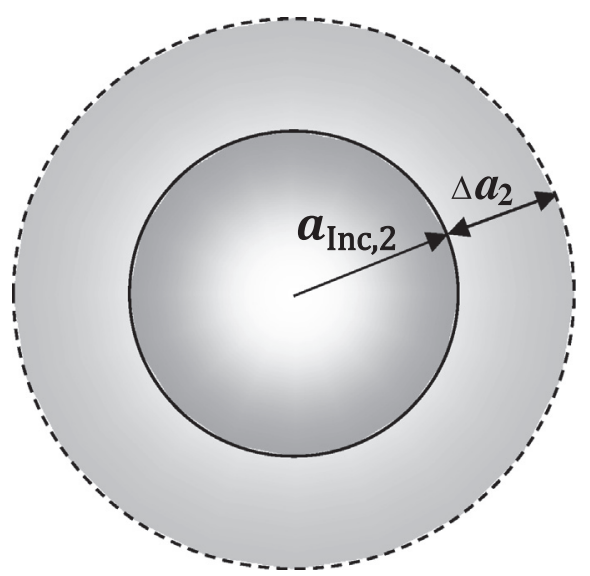

(b)

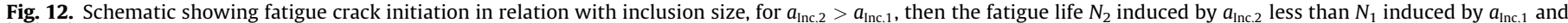
$\left|\frac{\mathrm{d} a_{2}}{\mathrm{~d} N}\right|>\left|\frac{\mathrm{d} a_{1}}{\mathrm{~d} N}\right|$.

result in a lower crack extension rate which is also referred to Fig. 12. Note also that the value of $\Delta \sigma_{R}$ is insensitive to the result and we take this value as $90 \%$ of the fatigue strength at the fatigue life of $10^{8}$ cycles, which is $783 \mathrm{MPa}$ for TT150 specimens and $666 \mathrm{MPa}$ for TT180 specimens. With the experimental data of the maximum applied stress, fatigue life, inclusion size and the value of $\Delta \sigma_{R}$, the values of average crack extension rate are readily calculated. These results are also shown in Fig. 11, which are compared with the data estimated from the present experimental results. It is seen that the data estimated from the Tanaka-Mura model are in fair agreement with the data from experiments except for the two points of TT150 specimens, which suggests that the crack extension rate in FGA region is very low by both approaches; in other words, for VHCF regime, the values of $\mathrm{d} a /\left.\mathrm{d} N\right|_{\mathrm{FGA}}$ are in the range between $10^{-12}$ and $10^{-13} \mathrm{~m} /$ cycle.

As discussed above and illustrated by Fig. 12, the inclusion size of crack origin has a major effect on the fatigue life. The data shown in Fig. 4 and Table 1 display a large scattering of fatigue life at the same stress level for TT150 specimens. The observations and measurements on the inclusions from which the cracks originate show that the range of inclusion size, $2 a_{\mathrm{Inc}}$, is between 20 and $60 \mu \mathrm{m}$ (Table 1 ), and the value is inversely proportional to the fatigue life. For $N_{f}$ between $10^{6}$ and $10^{7}$, the value of $2 a_{\text {Inc }}$ is ranging from 30 to $50 \mu \mathrm{m}$. For $N_{f}$ between $10^{7}$ and $4 \times 10^{8}$ (VHCF regime), the value of $2 a_{\text {Inc }}$ is ranging from 20 to $30 \mu \mathrm{m}$, which is substantially smaller than the size before VHCF regime. It is evident that the inclusion size is responsible for the large scattering of fatigue life, which is the weakest link phenomenon. The effect of inclusion size on fatigue strength and fatigue life was investigated in detail in our parallel paper [28].

\section{Conclusions}

The following conclusions are drawn from the present investigation on the propensities of crack initiation and early growth for high cycle fatigue and VHCF of a high carbon chromium steel.

1. For crack interior initiation for VHCF, there exists a characteristic dimension, i.e. the diameter of FGA, which corresponds to the threshold size of crack propagation.

2. The value of $\Delta K_{\mathrm{FGA}}$ is a constant and corresponds to $\Delta K_{\mathrm{th}}$ for a given material. The value is between 4 and $6 \mathrm{MPa} \mathrm{m}^{1 / 2}$ for the high strength steels.
3. The crack initiation life due to FGA is larger than $95 \%$ for the fatigue damage including VHCF regime and is larger than $99 \%$ for $N_{f}$ beyond $5 \times 10^{7}$ cycles.

4. Crack extension rate within FGA ranges from $10^{-11}$ to $10^{-12} \mathrm{~m} /$ cycle for $N_{f}$ between $10^{6}$ and $10^{7}$, and ranges from $10^{-12}$ to $10^{-13} \mathrm{~m} /$ cycle for $N_{f}$ between $10^{7}$ and $4 \times 10^{8}$.

5. Large scattering of $N_{f}$ is related to the large range of inclusion size distribution.

\section{Acknowledgements}

The authors would like to thank the financial support by the National Natural Science Foundation of China (Nos. 11172304, 11021262 and 11202210) and the National Basic Research Program of China (2012CB937500).

\section{References}

[1] Sakai T. Review and prospects for current studies on very high cycle fatigue of metallic materials for machine structural use. J Solid Mech Mater Eng 2009;3:425-39.

[2] Hong Y, Zhao A, Qian G. Essential characteristic and influential factors for veryhigh-cycle fatigue behavior of metallic materials. Acta Metall Sinica 2009;45:769-80

[3] Mughrabi H. Fatigue, an everlasting materials problem - still en vogue. Proc Eng 2010;2:3-26.

[4] Zimmermann M. Diversity of damage evolution during cyclic loading at very high numbers of cycles. Int Mater Rev 2012;57:73-91.

[5] Li SX. Effects of inclusions on very high cycle fatigue properties of high strength steels. Int Mater Rev 2012;57:92-114.

[6] Sakai T, Sato Y, Oguma N. Characteristic $S-N$ properties of high-carbonchromium-bearing steel under axial loading in long-life fatigue. Fatigue Fract Eng Mater Struct 2002;25:765-73.

[7] Duan Z, Shi H, Ma X. Fish-eye shape prediction with gigacycle fatigue failure. Fatigue Fract Eng Mater Struct 2011;34:832-7.

[8] Hong Y, Zhao A, Oian G, Zhou C. Fatigue strength and crack initiation mechanism of very-high-cycle fatigue for low alloy steels. Metall Mater Trans A 2012;43:2753-62.

[9] Murakami Y, Nomoto T, Ueda T. Factors influencing the mechanism of superlong fatigue failure in steels. Fatigue Fract Eng Mater Struct 1999;22:581-90.

[10] Shiozawa K, Lu L, Ishihara S. S-N curve characteristics and subsurface crack initiation behaviour in ultra-long life fatigue of a high carbon-chromium bearing steel. Fatigue Fract Eng Mater Struct 2001;24:781-90.

[11] Wang QY, Berard JY, Dubarre A, Baudry G, Rathery S, Bathias C. Gigacycle fatigue of ferrous alloys. Fatigue Fract Eng Mater Struct 1999;22:667-72.

[12] Tanaka K, Akiniwa Y. Fatigue crack propagation behaviour derived from $S-N$ data in very high cycle regime. Fatigue Fract Eng Mater Struct 2002;25:775-84. 
[13] Shiozawa K, Morii Y, Nishino S, Lu L. Subsurface crack initiation and propagation mechanism in high strength steel in a very high cycle fatigue regime. Int J Fatigue 2006;28:1521-32.

[14] Chapetti MD, Tagawa T, Miyata T. Ultra-long cycle fatigue of high-strength carbon steels. Part II: estimation of fatigue limit for failure from interna inclusions. Mater Sci Eng A 2003;356:236-44.

[15] Wagner D, Ranc N, Bathias C, Paris PC. Fatigue crack initiation detection by an infrared thermography method. Fatigue Fract Eng Mater Struct 2010;33:12-21.

[16] Li W, Sakai T, Li Q, Lu LT, Wang P. Reliability evaluation on very high cycle fatigue property of GCr15 bearing steel. Int J Fatigue 2010;32:1096-107.

[17] Zhao A, Xie J, Sun C, Lei Z, Hong Y. Effects of strength level and loading frequency on very-high-cycle fatigue behavior for a bearing steel. Int J Fatigue 2012;38:46-56

[18] Lei Z, Hong Y, Xie J, Sun C, Zhao A. Effects of inclusion size and location on veryhigh-cycle fatigue behavior for high strength steels. Mater Sci Eng A 2012;558:234-41

[19] Murakami Y, Endo M. Effects of defects, inclusions and inhomogeneities on fatigue strength. Int J Fatigue 1994;16:163-82.

[20] Liu YB, Li YD, Li SX, Yang ZG, Chen SM, Hui WJ, et al. Prediction of the $S-N$ curves of high-strength steels in the very high cycle fatigue regime. Int $\mathrm{J}$ Fatigue 2010;32:1351-7.

[21] Zhao A, Xie J, Sun C, Lei Z, Hong Y. Prediction of threshold value for FGA formation. Mater Sci Eng A 2011;528:6872-7.
[22] Sun C, Xie J, Zhao A, Lei Z, Hong Y. A cumulative damage model for fatigue life estimation of high-strength steels in high-cycle and very-high-cycle fatigue regimes. Fatigue Fract Eng Mater Struct 2012;35:638-47.

[23] Harlow DG, Wei RP, Sakai T, Oguma N. Crack growth based probability modeling of $S-N$ response for high strength steel. Int $\mathrm{J}$ Fatigue 2006;28:1479-85.

[24] Stepanskiy LG. Cumulative model of very high cycle fatigue. Fatigue Fract Eng Mater Struct 2012;35:513-22.

[25] Zhou C, Qian G, Hong Y. Fractography and crack initiation of very-high-cycle fatigue for a high carbon low alloy steel. Key Eng Mater 2006;324325:1113-6.

[26] Li YD, Yang ZG, Li SX, Liu YB, Chen SM. Correlations between very high cycle fatigue properties and inclusions of $\mathrm{GCr} 15$ bearing steel. Acta Metall Sinica 2008;44:968-72.

[27] Tanaka K, Mura T. A theory of fatigue crack initiation at inclusions. Metall Trans A 1982;13A:117-23.

[28] Sun C, Lei Z, Xie J, Hong Y. Effects of inclusion size and stress ratio on fatigue strength for high-strength steels with fish-eye mode failure. Int J Fatigue 2013;48:19-27.

[29] Wang QY, Bathias C, Kawagoishi N, Chen Q. Effect of inclusion on subsurface crack initiation and gigacycle fatigue strength. Int J Fatigue 2002;24:1269-74.

[30] Mughrabi $\mathrm{H}$. On the life-controlling microstructural fatigue mechanisms in ductile metals and alloys in the gigacycle regime. Fatigue Fract Eng Mater Struct 1999;22:633-41. 